\title{
The targeting of nutritionally at-risk children attending a primary health care facility in the Western Cape Province of South Africa
}

\author{
SE Schoeman ${ }^{1, *}$, MK Hendricks ${ }^{2}$, SP Hattingh ${ }^{3}$, AJS Benadé ${ }^{1}, J A$ Laubscher ${ }^{4}$ \\ and MA Dhansay ${ }^{1}$ \\ ${ }^{1}$ Nutritional Intervention Research Unit, Medical Research Council, PO Box 19070, Tygerberg 7505, South Africa: \\ ${ }^{2}$ School of Child and Adolescent Health, University of Cape Town, Rondebosch, Cape Town, South Africa: \\ ${ }^{3}$ Department of Health Studies, University of South Africa, Pretoria, South Africa: ${ }^{4}$ Biostatistics Unit, Medical \\ Research Council, Tygerberg, South Africa
}

Submitted 14 February 2005: Accepted 31 January 2006

\begin{abstract}
Aim: The aim of this study was to determine the practices of primary health care (PHC) nurses in targeting nutritionally at-risk infants and children for intervention at a PHC facility in a peri-urban area of the Western Cape Province of South Africa.

Methodology: Nutritional risk status of infants and children $<6$ years of age was based on criteria specified in standardised nutrition case management guidelines developed for PHC facilities in the province. Children were identified as being nutritionally atrisk if their weight was below the 3rd centile, their birth weight was less than $2500 \mathrm{~g}$, and their growth curve showed flattening or dropping off for at least two consecutive monthly visits. The study assessed the practices of nurses in identifying children who were nutritionally at-risk and the entry of these children into the food supplementation programme (formerly the Protein-Energy Malnutrition Scheme) of the health facility. Structured interviews were conducted with nurses to determine their knowledge of the case management guidelines; interviews were also conducted with caregivers to determine their sociodemographic status.

Results: One hundred and thirty-four children were enrolled in the study. The mean age of their caregivers was 29.5 (standard deviation 7.5) years and only 47 (38\%) were married. Of the caregivers, $77 \%$ were unemployed, $46 \%$ had poor household food security and $40 \%$ were financially dependent on non-family members. Significantly more children were nutritionally at-risk if the caregiver was unemployed (54\%) compared with employed $(32 \%)(P=0.04)$ and when there was household food insecurity $(63 \%)$ compared with household food security $(37 \%)(P<0.004)$. Significantly more children were found not to be nutritionally at-risk if the caregiver was financially self-supporting or supported by their partners (61\%) compared with those who were financially dependent on non-family members $(35 \%)(P=0.003)$. The weight results of the nurses and the researcher differed significantly $(P<0.001)$, which was largely due to the different scales used and weighing methods. The researcher's weight measurements were consistently higher than the nurses' $(P<0.00)$. The researcher identified $67(50 \%)$ infants and children as being nutritionally at-risk compared with $14(10 \%)$ by the nurses. The nurses' poor detection and targeting of nutritionally at-risk children were largely a result of failure to plot weights on the weight-for-age chart (55\%) and poor utilisation of the Road to Health Chart.

Conclusions: Problems identified in the practices of PHC nurses must be addressed in targeting children at nutritional risk so that appropriate intervention and support can be provided. More attention must be given to socio-economic criteria in identifying children who are nutritionally at-risk to ensure their access to adequate social security networks.
\end{abstract}

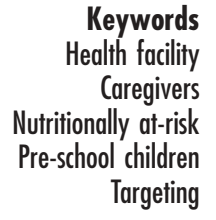

Contrary to the perception that undernutrition affects individuals only, it has affected families and communities for many decades and has emerged as a silent emergency ${ }^{1}$. Undernutrition contributes to half of the 10.8 million deaths that occur annually in the under- $5 \mathrm{~s}$ in developing countries; $90 \%$ of these deaths are caused by neonatal disorders, diarrhoea, pneumonia, malaria and HIV/AIDS ${ }^{2}$. Based on the conceptual model posited by the United Nations Children's Fund, the underlying causes of undernutrition are multifaceted and include problems relating to food security, care-giving practices, health service provision and the environment. Thus it remains a major 
challenge in most countries to address undernutrition comprehensively and effectively in children from communities where these underlying factors are prevalent ${ }^{1,3}$.

South Africa has made progress in developing a national nutrition policy, the Integrated Nutrition Programme (INP), which aims to reduce the problems of undernutrition in children based on a comprehensive and integrated approach $^{4,5}$. In addition, funding has been made available for nutrition-related provincial case management guidelines, as well as for implementation of the Integrated Management of Childhood Illness (IMCI) strategy, which aims to address the nutritional needs of children $<6$ years of age at primary health care (PHC) facilities ${ }^{4,5}$. Despite the implementation of these and other nutrition- and healthrelated measures, the prevalence of underweight (10\%) and stunting (25\%) of South African children remained static over a 5-year period ${ }^{6,7}$. Previous studies that were conducted prior to implementation of the INP revealed poor growth monitoring and promotion (GMP) practices, problems with the targeting of vulnerable groups, inadequate food supplementation and poor functioning of the former Protein-Energy Malnutrition Scheme ${ }^{8-17}$.

The aim of the present study was to determine the knowledge and practices of PHC nurses in targeting nutritionally at-risk children for intervention at a PHC facility.

\section{Methodology and study population}

A cross-sectional, descriptive study was conducted at a PHC facility in a low socio-economic peri-urban area of the Western Cape in South Africa, between 15 November 2001 and 15 January 2002. Based on the population census of 1996, the estimated population size of this area was 34306 , with the majority being coloured* (98\%) and a few black $(0.5 \%)^{18}$. The census data further revealed that $43 \%$ of the population was under the age of 15 years, $78 \%$ under the age of 35 years, while $13 \%$ comprised children under the age of 5 years $^{18}$. Unemployment, followed by low income, a high population growth rate and a high housing density were identified as the major problems in the community. These conditions, together with relatively easy access to the health facility and the absence of previous research undertaken in the area, contributed to the selection of this community for the study.

The participants consisted of infants and children aged 0-72 months, their caregivers and PHC nurses. The nursing staff had to work in the paediatric section of a health facility for at least 6 months to be selected for the study. For caregivers to be recruited, they had to

*The terms coloured, black and white are racial classifications formulated by the South African government during the Apartheid era to categorise people in three specific groups based on racial descent. The term coloured was used to indicate this group as being of mixed racial descent. accompany a child to the PHC facility and to reside in the area. These criteria were used to exclude nurses with inadequate working experience at a PHC facility or caregivers utilising the facility while visiting the area only.

A convenience sampling method was used to recruit caregivers and children. The nursing staff consulted caregivers immediately after registration and weighing of the children. Thereafter, the researcher recruited caregivers who had finished their consultation with the nurses and had no objection to participate in the study. This procedure was followed to ensure minimal disruption of the daily routine. Only if consultations were delayed did the researcher select a caregiver prior to consultation with a nurse. An average of three to five caregivers were recruited daily; at the end of the 2-month period, a total of 124 caregivers and 134 children were recruited and participated in the study.

The caregivers' and children's data were collected on a daily basis, while the data relating to the nurses were obtained towards the end of the study. Questionnaires were used to determine sociodemographic, health and nutrition information, and anthropometry of the children. The knowledge and practices of nurses regarding nutrition protocols were assessed. This was done by means of structured interviews and observation of nurses' weighing methods and practices.

The researcher used standard methods to obtain the weight and length/height of a sample of children and caregivers who attended the PHC facility ${ }^{19}$. Children were weighed in light clothing on a digital electronic load cell scale to the nearest $0.05 \mathrm{~kg}$. The scale was calibrated with a $1 \mathrm{~kg}$ standard weight and zeroed prior to each weighing session. Recumbent length of children $<2$ years was measured with a wooden board with a fixed headboard and a moveable footboard. The caregivers were asked to support the infant's head against the headboard while the researcher measured the infant's length. The height of children $\geq 2$ years was measured in the standing position with a stature meter that was fixed to the wall. Both length and height were measured to the nearest $0.1 \mathrm{~cm}^{19}$.

Anthropometric data obtained by the nurses and the researcher were analysed using Epi-Info version 6.0 (Centers for Disease Control and Prevention, Atlanta, GA, USA). The researcher used a growth chart based on the weight-for-age chart on the Road to Health Chart (RTHC) to plot the children's current and four previous weights obtained at the facility in order to interpret their growth curve. The advantage of obtaining four previous weights instead of two made it easier to identify weight errors or inconsistencies. For children, weight below the 3rd centile, birth weight less than $2500 \mathrm{~g}$, and flattening or dropping off of the growth curve for at least two consecutive monthly visits were used to classify the child as being nutritionally at-risk ${ }^{4}$. The prevalence of underweight, stunting and wasting was based on the proportion of children with $Z$-scores less than minus two standard 
deviations $(<-2 \mathrm{SD})$ below the median of the National Center for Health Statistics/World Health Organization reference values ${ }^{20}$. The researcher determined whether children identified as being nutritionally at-risk were referred to the Nutrition Supplementation Programme of the health facility-based programme and entered onto the register at the PHC facility. She also determined other nutrition interventions provided to those children who were nutritionally at-risk, e.g. vitamin $\mathrm{A}$ and iron supplementation and deworming.

\section{Results}

\section{Sociodemographic characteristics of caregivers, infants and children}

The study population comprised 124 caregivers and 134 pre-school children. Of the 124 caregivers, 105 (85\%) were the biological parents, 15 (12\%) were relatives and four (3\%) were non-family members. The mean age of the caregivers was 29.5 (SD 7.5) years. The mean age of the children was 19.0 (SD 17.8) months. Only 47 (38\%) caregivers were married, 18 (15\%) lived with a partner, 55 (44\%) were single and four (3\%) were divorced. Most caregivers, 96 (77\%), were unemployed; 72 (58\%) had one or two children, 38 (31\%) had three or four children and 14 (11\%) had five or more children. Household heads were indicated as follows: 45 (36\%) were the caregiver's spouse, 35 (28\%) the caregiver's parents, 25 (20\%) were the caregiver, 13 (10\%) were a relative of the caregiver, and six (5\%) a non-family member. Twelve (10\%) consumed alcohol regularly, six (5\%) consumed alcohol occasionally, 91 (73\%) never consumed alcohol, and 15 (12\%) had previously consumed alcohol but had stopped. Of the total sample of women $42(34 \%)$ were smoking. Of those who smoked, the majority were coloured 40 (95\%) compared with two (5\%) black. Forty-one (33\%) women also smoked during pregnancy.

Significantly more caregivers had children who were nutritionally at-risk if they were unemployed, 52 (54\%) $(P=0.04)$, compared with those who were employed, nine (32\%); and if there was household food insecurity (36; $63 \%)$ compared with household food security (25; 37\%) $(P=0.004)$. It was also found that significantly more caregivers who were financially self-supporting or supported by their partners $(46 ; 61 \%)$ had children who were not nutritionally at-risk $(P=0.003)$ compared with those who were not financially self-supporting or supported by their partners or a relative $(17 ; 35 \%)$ (Table 1).

\section{Weighing practices}

Differences were observed between the weighing practices of the researcher and the nurses. The nurses weighed the infants ( $<12$ months) without clothing on an infant scale and the children ( $\geq 12$ months) in light clothing on a bathroom scale. To ensure accuracy of weight readings, the nurses adjusted the infant scale's needle to zero at the start of the weighing session. The needle of the children's scale was not adjusted regularly and registered beyond zero at times. This observation was only made at the beginning of the weighing session and towards the end of the day. The researcher calibrated the scales with a $1 \mathrm{~kg}$ weight in the morning prior to the weighing and weighed all children in light clothing. The nurses weighed most children (95\%) either without or in light clothes and 5\% of the children fully clothed without their shoes.

\section{Completion of the RTHC}

The RTHC was available for 123 (92\%) children. When assessing completion of the weight-for-age chart, it was found that dates of birth were entered on $50 \%$, calendars were completed on $8 \%$, weights were plotted on $46 \%$, while only $4 \%$ had information on infant and or child feeding (Table 2). The researcher was able to assess children with underweight and growth faltering by obtaining four recent weights from the health facility records. These weights were plotted on a growth chart similar to the weight-for-age chart of the RTHC. This enabled the researcher to assess 67 (50\%) children as being underweight or faltering in growth. Since the nurses did not plot the weights of $55 \%$ of the children, they failed to detect a large number of children who were underweight or faltering in growth.

\section{Comparison of weight measurements}

Weights were available for comparison between the researcher and the nurses for 133 children. The mean

Table 1 Nutritional risk status of children based on sociodemographic status of the caregiver $(n=124)$

\begin{tabular}{|c|c|c|c|c|c|c|}
\hline \multirow[b]{2}{*}{ Nutritional risk status } & \multicolumn{2}{|c|}{ Employment status } & \multicolumn{2}{|c|}{ Household food security } & \multicolumn{2}{|c|}{ Financial support } \\
\hline & Employed & Unemployed & Secure & Insecure & Self/partner/relative & $\begin{array}{c}\text { Dependent on } \\
\text { non-family } \\
\text { members }\end{array}$ \\
\hline Not at risk & $19(67.9)$ & $44(45.8)$ & $42(62.7)$ & $21(36.8)$ & $46(61.3)^{\star \star \star}$ & $17(34.7)$ \\
\hline At risk & 9 (32.1) & $52(54.1)^{*}$ & 25 (37.3) & $36(63.2)^{\star *}$ & $29(38.7)$ & 32 (65.3) \\
\hline \multirow[t]{2}{*}{ Total } & $28(22.6)$ & $96(77.4)$ & $67(54.0)$ & $57(46.0)$ & $75(60.5)$ & 49 (39.5) \\
\hline & ${ }^{*} P=0.04$ & & ${ }^{* *} P=0.004$ & & ${ }^{\star \star \star *} P=0.003$ & \\
\hline
\end{tabular}

Values are given as $n(\%)$. 
Table 2 Growth monitoring and promotion (GMP) practices of nurses and their utilisation of the Road to Health Chart (RTHC)

\begin{tabular}{lc}
\hline GMP practices $(n=133)$ & $123(92.5)$ \\
Children's RTHC produced on date of survey & $127(95.5)$ \\
Children weighed without or in light clothes & $6(4.5)$ \\
Children weighed in heavy clothes (shoes, & \\
$\quad$ jerseys, jackets, etc.) & \\
Completion of the RTHC $(n=123)$ & $62(50.4)$ \\
$\quad$ Date of birth entered & $10(8.1)$ \\
Calendars completed & $56(45.5)$ \\
Weight plotted on the day of the survey & $5(4.1)$ \\
Infant/child feeding entered (breast, & \\
formula, solids) &
\end{tabular}

Values are given as $n(\%)$.

weight of all children obtained by the nurses and the researcher was $8.94 \mathrm{~kg}$ and $9.18 \mathrm{~kg}$, the mean weight for infants was $5.26 \mathrm{~kg}$ and $5.56 \mathrm{~kg}$, and the mean weight for children $11.44 \mathrm{~kg}$ and $11.66 \mathrm{~kg}$, respectively $(P<0.00)$. The researcher's measurements were consistently higher than the nurses' with the exception of the nurses' maximum weight measurement of $19.0 \mathrm{~kg}$ against the researcher's $18.3 \mathrm{~kg}$ for the same child (Table 3).

\section{Identification of nutritionally at-risk children}

The number of children with underweight identified by the researcher was 28 (21\%) compared with 34 (25\%) by the nurses. In addition, the researcher found that among the infants and children, 29 (22\%) were stunted and four (3\%) were wasted. The nurses had no information on stunting and wasting since height is not measured routinely at PHC facilities. Birth weights of 128 infants and children were obtained from clinic records and the children's RTHC, of whom 19 (15\%) were low birth weight. The researcher and nurses identified underweight and growth faltering in 67 (50\%) and 14 (10\%) of the children, respectively.

\section{Nutrition intervention for the nutritionally at-risk group}

Of the sample of 67 (50\%) nutritionally at-risk children identified by the researcher, the nurses' nutrition intervention was as follows: 14 (21\%) were registered on the Nutrition Supplementation Programme, 11 (16\%) received food supplements, three (4\%) received vitamin A supplements, 23 (34\%) received anthelmintics and 15 (22\%) received iron supplements (Table 4 ).

Follow-up visits

Follow-up visits were arranged for the following reasons: immunisations, 54 (40\%); treatment of disease, 38 (28\%); screening, five (4\%); and growth monitoring, $10(7 \%)$. Twenty-seven (20\%) children were not given a date or asked to return for follow-up.

\section{Training of nurses and their knowledge of nutrition case management guidelines}

None of the nurses $(n=12)$ received full training in implementing the nutrition case management guidelines. One $(8 \%)$ received formal training regarding the INP guidelines, which covered only the Nutrition Supplementation Programme, seven (58\%) received training in the IMCI strategy and primary health care, and four (33\%) received no training.

None of the nurses were knowledgeable about the recommended frequency of GMP visits for children aged 0-24 months, and only two (17\%) knew about the frequency of GMP visits for children aged 24-60 months.

All of the nurses (100\%) were knowledgeable about underweight and growth faltering as risk criteria for targeting children $<6$ years, while two (17\%) indicated that tuberculosis and HIV/AIDS were also risk criteria for this group. None of the nurses knew that underweight or body mass index $<18.5 \mathrm{~kg} \mathrm{~m}^{-2}$ was a criterion for supplementing lactating mothers, but five (42\%) indicated that teenagers who have no income, lack household food security or who have other social problems while breastfeeding their infants, needed support.

\section{Discussion}

Although the spouse/partner, caregiver or a relative headed $95 \%$ of the households in this study, this did not necessarily translate into optimal nutrition for many of the children ${ }^{1}$. The large number of caregiver-headed households (20\%) could influence the quality of life of mothers. It has been found that when mothers are exposed to long working hours, their child caring capacity can be diminished, while non-working mothers are often

Table 3 Comparison of weights $(\mathrm{kg})$ obtained by the nurses and the researcher $(n=133)$

\begin{tabular}{|c|c|c|c|c|}
\hline \multirow[b]{2}{*}{ Value } & \multicolumn{2}{|c|}{ Nurses' measurements } & \multicolumn{2}{|c|}{ Researcher's measurements } \\
\hline & $\begin{array}{c}<12 \text { months } \\
\quad(n=54)\end{array}$ & $\begin{array}{l}\geq 12 \text { months } \\
\quad(n=79)\end{array}$ & $\begin{array}{c}<12 \text { months } \\
\quad(n=54)\end{array}$ & $\begin{aligned} \geq & 12 \text { months } \\
& (n=79)\end{aligned}$ \\
\hline Mean & $5.26^{*}$ & $11.44^{\star \star}$ & $5.56^{*}$ & $11.66^{\star \star}$ \\
\hline Standard deviation & 1.78 & 2.75 & 1.84 & 2.6 \\
\hline Median & 4.75 & 11.00 & 5.15 & 11.2 \\
\hline Minimum-maximum & $2.2-10.5$ & $6.6-19.0$ & $2.4-11.0$ & $7.0-18.3$ \\
\hline
\end{tabular}


Table 4 Nutrition intervention by nurses for nutritionally at-risk children $(n=67)$

\begin{tabular}{lc}
\hline Entered in Protein-Energy Malnutrition Scheme register $14(20.8)$ \\
Vitamin A supplements received & $3(4.5)$ \\
Anthelmintic drugs received & $23(34.3)$ \\
Iron supplements received & $15(22.3)$ \\
Food supplements received & $11(16.4)$ \\
\hline
\end{tabular}

Values are given as $n(\%)$.

financially dependent on others for food and basic requirements. In either case, the children in these households are at risk of undernutrition ${ }^{1,21,22}$.

Fifty per cent of children were found to be nutritionally at-risk and factors such as unemployment, food insecurity and dependency on non-family members for financial support significantly increased the risk of undernutrition. It was also revealed that $48 \%$ of the caregivers were single and unsupported by their partners, which coincides with previous studies of children with undernutrition in similar communities $^{13}$. Since food availability at the household level is an important indicator of related social risks, the identification of food-insecure households needs to be strengthened and should be included with other criteria, e.g. household income, in targeting nutritionally at-risk children $^{1,3,5,6}$. Once such households are identified and targeted, access to the child support and care dependency grants as well as food supplementation could be initiated and facilitated via the PHC system or community points (unpublished data). This could improve social security measures for the caregivers and families with undernourished children.

In this study $34 \%$ of the caregivers smoked, which is probably related to the high prevalence of low birth weight in this population ${ }^{22}$. Similarly, another study in a neighbouring community, Bishop Lavis, between 1993 and 1995 showed that $60 \%$ of the women smoked and a low birth weight rate of $22 \%$ was reported for the children in this community (unpublished data). Since smoking and low birth weight are predominantly rife among coloured women, these trends need to be observed with the emerging racial integration among the different groups in South African communities.

A major limitation in GMP practices of nurses was under-utilisation of the RTHC with concomitant poor plotting and no entry of important nutrition-related information on the RTHC. Because of this, the nurses missed $84-95 \%$ of nutritionally at-risk children eligible for food and vitamin A supplements and nutrition monitoring recommended by the $\mathrm{INP}^{4}$. Other shortcomings in GMP related to poor maintenance, calibration and standardisation of scales as well as inaccuracies in weighing. Although the discrepancies between the weight measurements of the nurses and researcher were not extreme, the constant difference of 200-600g could affect the nutritional assessment of individual children. This was demonstrated in the small number of nutritionally at-risk children who were targeted to receive food supplements and the few caregivers receiving follow-up dates. In the long term, these shortcomings undermine strategies aimed at addressing undernutrition and promoting child survi$\mathrm{val}^{14,16}$. The consequences of poor GMP at PHC facilities have been documented in many studies, yet little has been done to change the situation ${ }^{10,12-17}$.

Given the poor socio-economic status of the population, the underweight prevalence of 21\% (researcher) and 25\% (nurses) in this study, which is twice the national mean of $10.3 \%$ for South African pre-school children, is not surprising ${ }^{6,7}$. Unlike studies targeting impoverished communities, national surveys include participants across the socio-economic spectrum, which could obscure a higher prevalence of underweight among vulnerable groups of children. Studies focusing on impoverished communities are therefore essential in targeting more vulnerable groups for nutrition intervention as suggested in the INP. It is also important that weighing equipment, methods and procedures are standardised to ensure reliable anthropometric outcomes and improved targeting of at-risk individuals.

The serious consequences of vitamin A deficiency and the benefits of vitamin A supplementation to mothers and children have been documented in numerous studies $^{5,21,22}$. A meta-analysis showed in six out of eight studies that vitamin A supplementation could reduce the all-cause mortality rate by $23 \%$ among children between the ages of 6 months and 5 years. It was found that improvement in vitamin A status was more likely to impact on mortality attributed to diarrhoeal disease and measles than on mortality attributed to respiratory infection or malaria $^{23}$. One trial showed that periodic vitamin A supplementation of HIV-positive children could reduce all-cause mortality by as much as $63 \%^{24}$. It was also found that HIV-infected infants born to mothers who were given vitamin A in the last trimester had better intestinal mucosal integrity when tested at 1-14 weeks, which was not found in non-infected infants ${ }^{22}$. Despite the proven benefits and cost-effectiveness of vitamin A supplementation and blanket deworming of children, these interventions were poorly implemented at the PHC facility ${ }^{1,21-23,25}$.

The training of nurses to improve GMP and the targeting of nutritionally at-risk children needs strengthening through the human resources development sub-directorate within the province. The feasibility of communitybased GMP and linking it to other community initiatives needs to be considered. For example, a community-based GMP system in the Langebaan community on the West Coast in the province has proved successful in facilitating $80-100 \%$ coverage and blanket deworming of pre-school children at 4 -month intervals over a 3 -year period ${ }^{17}$. This model has also facilitated community nutrition surveillance and monitoring, and the feasibility of utilising it in other urban communities should be tested ${ }^{17}$. Findings from the research undertaken indicate it is important that the emphasis on what is wrong be moved to how to 
address the current problems which are experienced in nutritional programmes ${ }^{26}$.

\section{Conclusion}

The research findings of this study highlight numerous shortcomings relating to implementation of the INP of the Department of Health at the primary level of care. There was poor targeting and intervention of nutritionally at-risk children by those given the task of implementing the INP. Factors contributing to this were the lack of training of PHC nurses, lack of supervision and nutrition monitoring, inconsistent GMP practices and the absence of community-based nutrition programmes to address underweight and poor food security in the long term. It is recommended that policy-makers urgently address these issues to ensure appropriate intervention for nutritionally at-risk children in similar communities.

\section{Acknowledgements}

We wish to acknowledge the assistance and support of Dr C de Villiers (City of Tygerberg); the nursing staff and the mothers of Delft Community Health Centre; Drs Sheik and Lawrence and Mrs Olivier (Provincial Administration of the Western Cape); and Dr C Lombard (Medical Research Council).

\section{References}

1 United Nations Children's Fund. The State of the World's Children. Geneva: World Health Organization, 1998.

2 Black RE, Morris SS, Bryce J. Where and why are 10 million children dying every year? Lancet 2003; 361: 2226-34.

3 Administrative Committee on Coordination/Sub-Committee on Nutrition (ACC/SCN). Fourth World Report on the World Nutrition Situation. Nutrition Throughout the Life Cycle. Geneva: ACC/SCN in collaboration with International Food Policy Research Institute, 2000.

4 Provincial Administration of the Western Cape (PAWC). Subdirectorates Nutrition and Maternal Child and Women's Health. Integrated Case Management Guidelines: Malnutrition. Cape Town: PAWC, 1999.

5 Department of Health. White Paper on the transformation of the health system in South Africa. Government Gazette 1997; 382(17910): 26-46.

6 Labadarios D, ed., supported by Steyn N, Maunder E, MacIntyre U, Swart R, Gericke G, Huskisson J, et al. The National Food Consumption Survey (NFCS). Children aged 1-9 years, South Africa, 1999. Technical Report. Stellenbosch: Department of Health, 2000.

7 South African Vitamin A Consultative Group (SAVACG). Anthropometric, vitamin A, iron and immunisation coverage status in children 6-71 months in South Africa. South African Medical Journal 1996; 86: 354-6.

8 Chopra M, Sanders D. Growth monitoring - is it a task worth doing in South Africa? South African Medical Journal 1997; 87: 875-7.

9 Cilliers L, Potgieter L, Malherbe D. Factors influencing poor progress of preschool children on the PEM-Scheme in Conville George. South African Medical Journal 1997; 87: 1242 .
10 Coetzee DJ, Ferrinho P. Nutritional status of children in Alexandra township. South African Medical Journal 1994; 84: $413-5$.

11 Hattingh SP. An evaluation of the nutritional status of preschool children in Venda. Unpublished Master's dissertation, University of South Africa, Pretoria, 1999.

12 Hendricks M, Perez E, Roberts M, Weight M. A prospective study of the growth of children under five years attending the Bishop Lavis malnutrition clinic. South African Journal of Epidemiology and Infection 2000; 15: 32-5.

13 Hendricks MK, Le Roux M, Fernandes M, Irlam J. Evaluation of a nutrition supplementation programme in the Northern Cape Province of South Africa. Public Health Nutrition 2003; 6: $431-7$.

14 Kuhn L, Zwarenstein MF, Thomas GC, Yach D, Conradie HH, Hoogendoorn L, et al. Village health workers and GOBI-FFF. An evaluation of a rural programme. South African Medical Journal 1990; 77: 471-5.

15 Malek E, Hussey G. Review of the PEM food scheme for children at district level, Western Cape, South Africa. South African Medical Journal 1997; 87: 1241.

16 Morley D, Elmore-Meegan M. Growth monitoring - a forgotten subject. Food, Nutrition and Agriculture 2000; 27: $14-18$.

17 Schoeman SE, Dhansay MA, Fincham JE, Kunneke E, Benade AJS. A community-based growth monitoring model to complement existing health practices in a semi-urban town on the west coast. South African Journal of Clinical Nutrition 2003; 16: 126-32.

18 Statistics South Africa. Population Census, 1996. Community profile databases. Report on CD-ROM, Number 03/01-30 (1996). Available from tracyd@statssa.gov.za

19 Jeliffe DB, Jeliffe EFP. Community Assessment with Special Reference to Less Technically Developed Countries. Oxford: Oxford University Press, 1989.

20 World Health Organization/Programme of Nutrition. WHO Global Database on Child Growth and Malnutrition [online]. Available at http://www.who.int/nutgrowthdb/intro. Accessed 22 December 2004.

21 Allen LH, Gillespie, SR. eds. What Works? A Review of the Efficacy and Effectiveness of Nutrition Interventions. United Nations Administrative Committee on Co-ordination/SubCommittee on Nutrition (ACC/SCN) Nutrition Policy Discussion Paper No. 19/Asian Development Bank (ADB) Nutrition and Development Series No. 5. Geneva/Manila: ACC/SCN in collaboration with ADB, 2001.

22 World Health Organization (WHO). Life in the 21st Century: A Vision for All. 1998 World Health Report. Geneva: WHO, 1998.

23 Beaton GH, Martorell R, Aronson KJ, Edmonston B, McCabe G, Ross AC, et al. Effectiveness of Vitamin A Supplementation in the Control of Young Child Morbidity and Mortality in Developing Countries. United Nations Administrative Committee on Co-ordination/Sub-Committee on Nutrition (ACC/SCN) State-of-the-Art Series Nutrition Policy Discussion Paper No. 13. Toronto: International Nutrition Program, Faculty of Medicine, University of Toronto, December 1993.

24 Fawzi W, Mibise R, Hertzmark E, Fataki M, Herrera G, Ndossi $\mathrm{G}$, et al. A randomized trial of vitamin A supplements in relation to mortality among human immunodeficiency virusaffected children in Tanzania. Paediatric Infectious Disease Journal 1999; 18: 127-33.

25 Fincham JE, Evans AC, Dhansay MA, Yach D. The case for mass treatment of children endemically infected by worms. MRC News 1996; 27: 6.

26 Berg A. Sliding toward nutrition malpractice: time to reconsider and redeploy. American Journal of Clinical Nutrition 1992; 57: 3-7. 